\section{Health and inequality: institutions and public policies in the 21st century}

\author{
Ligia Giovanella, ${ }^{1}$ Jeni Vaitsman, ${ }^{1}$ \\ Sarah Escorel, ${ }^{1}$ \\ Rosana Magalhães, ${ }^{1}$ \\ and Nilson do Rosário Costa ${ }^{1}$
}

A key characteristic of Latin American countries has been the association between extreme inequality and intense poverty, along with the inability of previous social and economic policies to alleviate these conditions. In recent decades, fiscal adjustment policies proposed by international financial agencies have led to monetary stability, but by focusing solely on economic growth, they have intensified the preexisting poverty and inequality.

For some time, studies on the relationship between a population's living conditions and state of health have corroborated that health and disease have social determinants. There is also evidence that the poor have less access to health services and encounter difficulty obtaining comprehensive, caseresolving care for diseases, even when such care is guaranteed as a universal right. Still, few studies have established a more precise relationship between social justice at a broader level and equity in health, as expressed through policies, programs, and actions.

A seminar entitled "Health and Inequality: Institutions and Public Policy in the 21st Century" was held under the auspices of the Brazilian National School of Public Health/Oswaldo Cruz Foundation (ENSP/FIOCRUZ) and the Pan American Health Organization (PAHO) on 29 November through 1 December 2001 in Rio de Janeiro. It explored the relationships among health, inequality, and poverty in the realm of health public policy, institutions, and programs. The seminar covered the following topics: situations of vulnerability and their relationship to living conditions and health care; the influences of political and civic tradition and institutional performance on the extent of inequality and poverty; and innovations in the field of social policy designed to guarantee protection of health with equity. The seminar also sought to identify gaps in knowledge and methods for the evaluation of public policies.

A common agenda for research and technical cooperation among the participating institutions was also launched at the seminar. It is hoped that implementing this agenda will foster scientific collaboration by institutions of excellence at the national and international levels and create institutional conditions conducive to linkage between the production of knowledge and public policy management, so that research activities may respond to the needs of managers of the Brazilian public health system, the Unified Health System (UHS).

The seminar consisted of two addresses, a roundtable, and three workshops. The opening presentation was by Dr. Juan Antonio Casas (Director of 
the Division of Health and Human Development, PAHO), who gave an overview of health inequalities in Latin America. Next, Prof. Paul Pierson (School of Government, Harvard University) lectured on the restructuring of welfare states in affluent democracies, including cost-containment processes, "recommodification," and "recalibration" of social programs in a context of austerity. He identified possibilities and constraints for the implementation of policies aimed at reducing inequalities.

During the roundtable, Dr. Sonia Rocha analyzed poverty in Brazil. She emphasized that monetary parameters provided a limited means of characterizing the problem and proposed that life expectancy was the most sensitive indicator of poverty. She also highlighted the need to develop new approaches to public policy design that take into account poverty and social inequalities. Prof. Elisa Reis (Federal University of Rio de Janeiro) presented the results of a study on perceptions of the elite sector of society concerning poverty and inequality in Bangladesh, Brazil, India, and South Africa. Prof. Reis pointed out that understanding these perceptions is important because of the critical role the elite play in the formulation and implementation of social policies. Their perceptions of poverty and inequality have major implications for the ways societies deal with these problems, since social protection systems are based on society's shared values. She found that people in Brazil's elite class acknowledge the country's huge prevailing inequalities, but they do not feel responsible for these problems. Rather, they trust the State-which is seen as separate from society-to find solutions. The elite see themselves as socially separate from the poor rather than as part of the same whole, thus hindering the adoption of collective solutions to social problems.

Prof. Amélia Cohn (University of São Paulo) noted that after the Brazilian intellectual and social movement succeeded in getting the Unified Health System written into the 1988 Constitution, political issues faded from view and greater emphasis was placed on managerial and technical issues. In Cohn's view, two important social questions are how to deal with growing social exclusion in a context where social inclusion no longer occurs through work and how to promote the market while guaranteeing consumers' right to choice. She emphasized the need to revisit some health reform alternatives in Brazil and to link social inclusion, equity, and social justice as indissoluble, inherent dimensions of democracy.

The subjects of the three workshops were "Poverty, Social Inequalities, and Equity in Health," "Institutions, Politics, Culture, and Inequality," and "Public Policy Prospects for Building Equity in Health."
The "Poverty, Social Inequalities, and Equity in Health" workshop sought to promote in-depth discussion of vulnerability among social groups, analytical methodologies, and effective policy alternatives for combating poverty and reducing social and health inequalities. Adopting a broad perspective toward needs and hardships, discussion centered on the ways in which such characteristics as gender, race or ethnicity, education, work skills, membership in associations or religious groups, weakness or solidity of family ties, and insufficient economic resources might substantially modify both the experience of vulnerability and prospects for alleviating it. Some groups are affected by several associated or overlapping vulnerabilities that pave the way for social exclusion. Greater effort is required to better define the situation of these groups and monitor the impact of social policies and programs.

The discussions were framed by the following questions: 1) What are the main trends in poverty and inequality in Latin America? and 2) What are the main social and political alternatives and innovations that will help guarantee greater equity in health, in light of differences in social vulnerability (gender, race, ethnicity, income)?

The papers presented ${ }^{2}$ emphasized the importance of characterizing poverty and inequalities in Brazil based on indicators that could capture the complexity of these phenomena. Income was used as the initial parameter for conducting other analyses that considered the impact of gender, race or ethnicity, education, place of residence, and other important divisions on social inequalities. Since health indicators are extremely sensitive tools for an analysis of social inequality, it is expected that the health sector will play the leading role in formulating and implementing intersectorial policies for the reduction of social inequalities. Differential access to public services, especially health and education, aggravates inequalities. The ideas of social, cultural, and symbolic capital serve as the basis for revealing and analyzing different patterns of destitution. New methodologies, such as the analysis of educational transitions in relation to life cycles, ${ }^{3}$ in which vari-

\footnotetext{
2 The papers were: "Some Points of Consensus on Poverty in Brazil," by Sonia Rocha; "Family Resources and Educational Transitions," by Nelson do Valle Silva and Carlos Hasenbalg (Institute for University Research of Rio de Janeiro); "Poverty, Assets, and Health in Brazil," by Wagner L. Soares (Fluminense Federal University-UFF) and Marcelo Neri (Getúlio Vargas Foundation, Rio de Janeiro-FGV-RJ); "Racial Inequalities: A Summary of Indicators and Challenges in the Field of Public Policies," by Rosana Heringer (Cândido Mendes University); and "Poverty, Inequality, and Equity in Health: Remarks from a Cross-Cutting Gender Perspective," by Karen Giffin (ENSP). Participants in the discussions were Maria do Carmo Leal (ENSP/FIOCRUZ) and Amélia Cohn (University of São Paulo-USP).

3 Silva NV, Hasenbalg C. Family resources and educational transitions. Paper presented at the Seminar on Health and Inequality: Institutions and Public Policies in the 21st Century, Rio de Janeiro, Nov-Dec 2001
} 
ous determinants assume different roles over the course of the process, are important tools for exploring and explaining social vulnerabilities.

A situational and structural transformation in Brazil's fragmented standard of social protection will require alternative strategies that improve links between the compensatory and redistributive aspects of measures to combat social inequality. In general, the lack of coordination among social programs-whose main impact has been to create a country of recipients and persons who lack civic values-must be rectified in order to improve targeting and selectivity without losing sight of the universal nature of social rights. Establishing consistent priorities and targets in Brazil while at the same time building and strengthening citizenship and social rights is a major challenge for policies to combat poverty and inequality in the 21st century.

The "Institutions, Politics, Culture, and Inequality" workshop focused on the relationships among political and civic development, institutional performance, and poverty and inequality. Discussion centered on the influence of deeply ingrained social practices and norms on political values and culture in different spheres of social action, as well as their consequences for public policy performance in relation to poverty and specific types of inequalities in Brazilian and Latin American society.

Questions underlying this workshop were how Brazilian and Latin American political and civic tradition influences the quality and efficacy of institutions as well as the extent of inequality and poverty, and whether it is possible to incorporate Brazilian cultural tradition into the formation of positive new institutional arrangements and new paradigms for collective action and social responsibility. The ensuing discussions focused on recent changes in relationships among the State, the market, and civil society.

The presentations considered the following topics: changes in the policy matrix in which social policies and specific civic responsibilities in Latin America were designed and implemented; the views of opinionmakers from different segments of the health field regarding main trends in the Brazilian health system; the role of "health councils" in the production of a virtuous circle for accumulating social capital and strengthening democracy; and a case study on implementation of a "participatory budget," which analyzed how incorporation of the community into management of public policies is influenced by preexisting political conflict and relationships. ${ }^{4}$

\footnotetext{
4 The papers presented were: "From Contact to Disintegration: Citizenship and Social Policies in Latin America," by Marcelo Cavarozzi (School of Policy and Government, San Martín University, Buenos Aires); "Trends in the Brazilian Health System," by Sérgio Piola and Solon Magalhães Vianna (Institute for Applied Economic Research);
}

In recent years Brazil has seen numerous positive experiences in community participation, formation of social capital, and strengthening of democracy, along with a redefinition of the State's role. On the other hand, these positive developments have coexisted with the growth of poverty and inequalities and increasingly visible corruption.

Case studies on the participatory budget and health councils in the state of Rio de Janeiro were discussed. These initiative are components of a new institutional design created by the 1988 Constitution, which promotes the development of a civic and democratic culture and the formation of social capital. These new participatory practices have emerged as an alternative to the "State-versus-market" dichotomy and place civil society in a position to monitor public policies. Such initiatives can thus be viewed as institutional mechanisms that allow for a break with "traditional" political practices. However, these experiences "do not occur in a sociological vacuum . . . , but are faced with historically constituted forms of political sociability and interaction with government." ${ }^{5}$ As mentioned above, it is common for innovations to be reshaped by local culture and conflicts.

The discussion acknowledged that social and political processes always involve permanence and change simultaneously. The challenge is to seek institutional and political pathways that strengthen democracy as well as social, political, and symbolic inclusion.

The workshop entitled "Public Policy Prospects for Building Equity in Health" examined the degree to which health policy reforms and innovations have promoted equity in health protection. In the last two decades, faced with economic, political, and ideological pressures, several countries undertook various forms of health system reform. After an intensive effort to implement conservative approaches and restructure social protection systems, the question of the repercussions of these reforms on inequalities in coverage and access remains unresolved.

The workshop presentations and discussions focused on three groups of issues: recent specific health reforms in Latin America; impact of reforms and innovations on equity in the utilization of health services; and solutions to the dilemma of targeting versus universalization. The papers presented dealt with a comparison of reforms and

\footnotetext{
"Associations, Participation, and Civic Culture: The Potential of the Health Councils," by Maria Eliana Labra (ENSP/FIOCRUZ); and "Community Participation and Struggles for the Political Domain," by Marcos Otávio Bezerra (UFF). Participants in the discussions were Dr. César Vieira (PAHO), Dr. Nelson Ibañez (FGV-RJ), and Dr. Antonio Ivo de Carvalho (ENSP/FIOCRUZ).

5 Bezerra, MO. Community participation and struggles for the political domain. Paper presented at the Seminar on Health and Inequality: Institutions and Public Policies in the 21st Century. Rio de Janeiro; Nov-Dec 2001.
} 
models for social protection of health in Latin America; an evaluation of public health system decentralization in Brazil; a critical review of primary care as a priority in the Brazilian public health care system; new health care models; and the consequences for equitable access of new management models in which public and private clienteles use public health care units. ${ }^{6}$

Health system reforms in Latin America have been more radical than in North American or European countries. Changes in internal components of the health system have been linked to changes in coverage. Three models for restructuring coverage can be identified: encouragement of private insurance for high-income sectors of the formal labor market (Chile); differentiated public insurance according to income and position in the labor market (Colombia); and universal coverage financed by taxes (Brazil).

Workshop participants viewed Latin American health reforms as public policies that offer extended coverage to the poor, but they contended that such reforms have done little to reduce inequalities. In Chile a dual model with extensive privatization was created; in Colombia a plural, segmented model; and in Brazil a universal model, with protection guaranteed by the State. In all three cases the reforms led to expanded coverage, but inequality tended to worsen where access depended increasingly on individual and family finances to purchase services in the private health sector.

In Brazil, health protection reform was designed to create a universal and egalitarian system. Coverage has expanded, even in the face of heavy pressure. Still, part of the population enjoys double coverage by having access to care via both the public system and the for-profit system through private health insurance. As in Chile, different segments of the population in Brazil have different coverage; however, in Chile the dual system is structural, while in Brazil it is functional as a consequence of overlapping coverage. In Colombia the various types of insurance cover only $50 \%$ of the population.

A major obstacle to greater equity and expanded protection of health in Latin American

\footnotetext{
6 The following papers were presented: "Universal, Dual, or Plural? Health Care Models and Dilemmas in Latin America," by Sônia Fleury (FGV-RJ); "Equality and Efficiency in Health Reforms: Lessons from the Brazilian Case," by Ana Luiza Viana et al. (Social Medicine Institute; University of Campinas); "The Unified Health System (SUS) and Basic Health Care: The Search for a New Design," by Rosa Maria Marques and Áquila Mendes (FEA/PUC- São Paulo); "Promotion and Surveillance in the Context of Health Care Regionalization in the Unified Health System," by Carmen Fontes Teixeira (Institute of Collective Health, Federal University of Bahia); and "New Forms of Management in the Health Sector: Redefinition of the StateOwned Public Sector from the Perspective of Social Inclusion or Exclusion," by Paulo Elias (USP). Participants in the discussions were Alicia Ugá (ENSP/FIOCRUZ), Célia Almeida (ENSP/FIOCRUZ), Eleonor Conill (Federal University of Santa Catarina), and Sílvia Gerschmann (ENSP/FIOCRUZ).
}

countries is their social protection systems. Stratified inclusion is accompanied by exclusion of broad segments of the population, producing the socalled "path dependence effect" that influences reforms. $^{7}$

Evaluations of the decentralization process in Brazil have shown that in recent years more municipalities have assumed the responsibility of ensuring coverage of health care at greater levels of complexity. A correlation has been observed between the local system's greater case-resolving capacity and the robustness of the local administrative apparatus. However, despite improved geographic distribution of systems with increased case-resolving capacity, major regional disparities remain, due to fiscal constraints and the country's burdensome legacy of economic and social inequalities.

Regarding the dilemma between an emphasis on basic care and guaranteed care at all levels of complexity, the discussion pointed out that prioritizing primary care can result in a lack of guaranteed access to necessary care for more complex cases. The question arises of how an emphasis on basic care differs from proposals for targeting and a minimum basket of services.

The evaluation of the Family Health Program (a primary health care program currently being implemented in Brazil) was inconclusive. There are concerns that the program is a targeting policy in disguise that works against equity in health care utilization by setting a standard of less complex services for the poor. On the other hand, the program can become a gateway to the system and, if integrated into the health services network, can promote comprehensive care. In Brazil, expansion of basic care has contributed to inclusion of more of the country's population in the health care system, but at present only some of the country's municipalities (containing $37 \%$ of the total population) are capable of guaranteeing health care at all levels of complexity. ${ }^{8}$

As a result of new forms of management implemented through public-private partnerships, low-income segments of the population are jeopardized and suffer discrimination as public services embrace market mechanisms. Inequities in treatment regimens, access, and scheduling of appointments have been observed, as well as a trend towards staff specialization to serve private users. Middle-class private users resist sharing the network and treatment facilities with users who de-

\footnotetext{
7 Fleury S. Universal, dual, or plural? Health care models and dilemmas in Latin America. Paper presented at the Seminar on Health and Inequality: Institutions and Public Policies in the 21st Century. Rio de Janeiro; Nov-Dec 2001.

8 Viana, AL. Equality and efficiency in health reforms: lessons from the Brazilian case. Paper presented at the Seminar on Health and Inequality: Institutions and Public Policies in the 21st Century. Rio de Janeiro; Nov-Dec 2001.
} 
pend exclusively on the public health system, thereby sparking discriminatory measures.

Key questions regarding the issue of targeting versus universalization are how systems based on equality will deal with diversity, as in the Brazilian case, and how care can be distributed on the basis of need without segmentation of the system. In order to obtain equity in health, public policy must address inequality and social exclusion, two problems that require different treatments. An emphasis on the poor that does not aim at reducing inequalities merely leads to narrowly targeted responses, which can have disastrous consequences for attempts to guarantee universal social rights.

In conclusion, the discussion recognized that the Brazilian problem is not just one of diversity, which exists in any system, but rather reflects the intensity of differences and inequalities in the society. Social policies can ameliorate inequality, but they are not sufficient to do so alone. They must be linked to redistributive economic policies and must deliver more than services, by promoting symbolic and cultural changes and contributing to the achievement of citizens' rights.

As a development of the workshops, several research topics were suggested for a cooperative research agenda involving the Brazilian National School of Public Health, PAHO, managers from the Unified Health System, and other participating institutions. The topics pertained to analysis and evaluation of health inequalities and their relationship to public policies, culture, and institutions:

- problems of coordination and integration of programs and policies among the sectors responsible for national social policies, organizations from civil society, the private sector, and international agencies

- participation by civil society in formulating policies, taking into account cultural, political, and civic tradition, and in monitoring their impact on the performance of the Unified Health System

- the performance of institutions in specific social, political, and cultural contexts

- analysis of health reforms and their impact on equity, considering differences in economic adjustment, governance, reform coalitions, degree of institutionalization of social programs, and political culture

- utilization of UHS resources and the impacts of Federal financial incentives on municipalities, as well as experiences at the state level, where managers have implemented their own financial incentives

- strategies used to reduce regional inequalities in the availability of human resources

- health care unit management, quality of care, and comprehensive scope of care in health care models for local health systems
- analysis of the sharing of public health services by public and private users, with an emphasis on identifying discriminatory practices that produce inequalities, for the purpose of guiding the hiring of health care providers

- the managerial, network/organization, and technical dimensions of health care models

The need to incorporate equity as a principle in policy objectives was reaffirmed. Toward that end, a dialogue was proposed between managers and researchers in order to foster equitable policies and research.

Finally, to develop the proposed agenda it was suggested that multicenter studies be conducted. The involvement of multiple institutions would allow for a broader view of health policies, continued encouragement of interinstitutional links, decreased costs, and greater methodological efficiency.

\section{SINOPSIS}

\section{Salud y desigualdad: instituciones y políticas públicas en el siglo XXI}

Este trabajo informa acerca del contenido del seminario "Salud y desigualdad: instituciones y políticas públicas en el siglo XXI", patrocinado por la Escuela Nacional de Salud Pública de Brasil/Fundación Oswaldo Cruz y la Organización Panamericana de la Salud, que tuvo lugar del 29 de noviembre

1 de diciembre de 2001 en Rio de Janeiro, Brasil. El seminario constó de dos discursos que proporcionaron una perspectiva general de las desigualdades sanitarias en América Latina y de las politicas recientes destinadas a reducir estas desigualdades, de una mesa redonda que analizó las investigaciones sobre las raíces sociales de la pobreza en Brasil, y de tres talleres, el primero de los cuales trató de la pobreza, las desigualdades sociales y la equidad en el campo de la salud. Los participantes presentaron un análisis detallado de las vulnerabilidades de los grupos sociales y de las innovaciones en las políticas para combatir la pobreza y reducir las desigualdades sociales y sanitarias. El segundo taller, titulado "Instituciones, politicas, cultura y desigualdad", se centró en la influencia de las tradiciones culturales y políticas latinoamericanas en las instituciones y en la magnitud de la pobreza y la desigualdad. Se estudiaron nuevas iniciativas para aumentar la participación comunitaria en la vigilancia y gestión de las políticas públicas, fortaleciendo así la democracia. El tercer taller exploró las perpectivas de las políticas públicas para desarrollar la equidad en el campo de la salud. Se revisaron las repercusiones de las reformas de los sistemas de salud de América Latina en el acceso a los servicios y se compararon los planes de aseguramiento adoptados en Brasil, Chile, y Colombia. Los tres talleres proporcionaron una lista de temas para posibles proyectos de investigación conjunta entre los patrocinadores del seminario y otras instituciones. Los participantes del seminario concluyeron que los investigadores y los gestores del sistema de salud necesitan trabajar juntos para promover el desarrollo de políticas y programas equitativos. 